\title{
PEMODELAN KNOWLEDGE MANAGEMENT BERBASIS WEB DAN PEMBENTUKAN KOMUNITAS PRAKTISI BIDANG PROJECT MANAGEMENT
}

\author{
Umama \\ Program Studi Sistem Informasi, STMIK Atma Luhur \\ Jl. Raya Sungailiat, Selindung Lama, PangkalanBaru - Bangka \\ E-mail : umama.umi@gmail.com
}

\begin{abstract}
Abstrak
Penyelenggaraan project management di Indonesia berlandaskan pada dua metode, yaitu dengan menggunakan pedoman standarisasi Internasional dan menggunakan referensi best practise yang didapat dari pengalaman para Praktisinya. Untuk memfasilitasi kegiatan tersebut, diperlukan sebuah media penampungan, penyajian dan berbagi pengetahuan berupa Knowledge Management serta pembentukan komunitas yang keanggotaannya relatif lebih mudah dan murah. Penelitian ini akan membuat sebuah Pemodelan Knowledge Management System berbasis web dan Pembentukan Komunitas Praktisi bidang Project Management, yang meliputi tiga tahapan utama siklus pengembangan knowledge management yaitu knowledge capturing, knowledge sharing and dissemination dan knowledge acquisition and application.
\end{abstract}

KataKunci:knowledge management, project management, web, pemodelan

1. PENDAHULUAN

\subsection{Latar Belakang}

Project Management yang baik, dikatakan berhasil apabila bisa mencapai sasaran penyelenggaraan proyek dengan tepat dan sesuai dengan waktu yang telah ditentukan. Project Management Institute (PMI) telah mengeluarkan alat bantu bagi seorang Manajer Proyek tentang bagaimana mengelola proyek dengan baik untuk hasil yang maksimal melalui standarnya yaitu Project Management Body of Knowledge $(P M B O K)$, yang memuat secara detil mengenai proses, alat bantu serta dokumentasinya.

Pada dasarnya, sebuah metode Project Management dari Project Management Institute (PMI) tersebut berlaku dan bisa diterapkan pada semua jenis industri. Namun, seiring dengan meningkatnya kebutuhan organisasi atau perusahaan yang beragam yang seringkali bertolak belakang dengan sumber dayanya yang terbatas, kebutuhan proyek pun menjadi sangat beragam, maka seringkali teori pengelolaan proyek yang tercantum dalam Project Management Body of Knowledge (PMBOK) perlu disesuaikan dengan kondisi nyata di lapangan. Sehingga, penggunaan Project Management Body of Knowledge (PMBOK) sesuai dengan kultur tiap jenis proyek serta gaya dari masing-masing Manajer Proyek.

$$
\text { Dengan demikian, nantinya }
$$

berkembanglah Project Management - best practice, yaitu yang diperkaya dengan knowledge yang didapat dari pengalaman para
Project Manager serta anggota tim proyek yang lain.

Secara ringkas, hal - hal yang melatarbelakangi penelitian ini yaitu:

1. Sebuah proyek bersifat temporer, biasanya tim proyek hanya bekerjasama dalam masa temporer tersebut, sehingga jika proyek selesai maka tim proyek pun berakhir. Oleh karena itu, sangat disayangkan jika knowledge tersebut hanya dimiliki oleh masing-masing tim proyek tanpa bisa dibagi dengan praktisi lain yang akan mengelola proyek kelanjutan dari yang sebelumnya atau proyek lain yang serupa.

2. Bagi sebuah Perusahaan, pembentukan tim proyek baru berarti kembali harus memulai segala sesuatunya dari awal, penyelarasan keahlian tim dari awal pula, ini berarti tambahan beban upaya bagi Perusahaan.

3. Sedikitnya sarana penyediaan knowledge untuk project management yang berbasis best practise, menyebabkan sebagian praktisi hanya bekerja berdasarkan teori saja, sehingga bersifat kurang flexible, kurang bisa menyesuaikan keahliannya dengan kondisi proyek yang sedang dikelola.

4. Penanganan project management padaIndustri yang berbeda (perbankan, telekomunikasi, konstruksi, oil and gas dan sebagainya) kadang kala berbeda, sehingga praktisi project management memerlukan referensi sebanyak mungkin mengenai hal tersebut. 
5. Belum ada komunitas praktisi project management yang lebih umum dan sederhana, karena komunitas yang sudah ada biasanya berbentuk asosiasi atau organisasi yang resmi seperti PMI atau CCTA.

\subsection{Identifikasi Masalah} ini yaitu:

Hal - hal yang akan diteliti pada penelitian

1. Bagaimana merancang suatu model knowledge management system yang tepat guna, yaitu di mana knowledge yang tersedia benar - benar memenuhi kebutuhan penggunanya (dengan cara memaksimalkan proses knowledge capture dan knowledge update),serta proses knowledge sharing berjalan dengan baik.

2. Bagaimana menyeimbangkan content dalam KMS bidang project management ini, antara yang berdasarkan teori (literatur) dengan pengalaman best practise para praktisi

\subsection{Tujuan Penelitian}

Sebuah Pemodelan Knowledge Management System Berbasis Web danPembentukan Komunitas Praktisi Project Management ini bermaksud untuk memetakan dan mendokumentasikan serta sebagai sarana sharing semua knowledge yang berkaitan dengan Project Management, baik secara teori standar maupun pengalaman orang-orang proyek, sehingga pada akhirnya didapatlah sebuah Project Management - best practice, yang semakin mempermudah komunitas manajemen proyek (mulai dari Project Manager, Bussiness Analyst, Project Admin, Project Control, Project Owner, dan sebagainya) dalam mengelola proyeknya dengan benar dan berhasil.

Dengan memaksimalkan proses knowledge capture untuk memperoleh knowledge dasar yang tepat, serta penyusunan prosedur penggunaan KMS yang mengikuti falsafah KM yang benar (di mana harus ada proses knowledge sharing), diharapkan implementasi KMS ini nantinya bisa berhasil dan tidak mengulang kegagalan - kegagalan implementasi KMS pada umumnya.

Selain itu, dengan adanya pembentukan komunitas praktisi project management, diharapkan KMS ini dapat membantu:
a. Mengembangkan keterampilan profesional anggota.
b. Memfasilitasi jaringan dan kolaborasi yang efektif.
c. Mensosialisasikan standarisasi umum yang digunakan untuk bidang project management.

\subsection{Ruang Lingkup}

Pembahasan yang akan dikaji lebih lanjut dalam penelitian ini hanya mencakup hal - hal berikut:

1. Knowledge Management System (KMS) Roadmap, meliputi:

a. Proses pembentukan knowledge dasar untuk bidang Project Management (proses capturing) hingga terbentuknya pemetaan knowledge tersebut.

b. Perencanaan knowledge management tool (KM Tool), mulai dari pemilihan tool, pengaturan menu dan penggambaran mock up.

c. Perancangan strategi implementasi KMS, meliputi penyusunan beberapa standard operating procedure (SOP) seperti prosedur keanggotaan komunitas KMS, penyusunan prosedur knowledge sharing antar anggota komunitas dan penyusunan prosedur pengelolaan dan pemeliharaan KMS, serta gambaran evaluasi performa KMS melalui metode pengukuran knowledge management maturity level berdasarkan knowledge management maturity model (KMMM).

2. Analisa manfaat (benefit analysis) dari penerapan KMS untuk komunitas praktisi Project Management.

\section{TINJAUAN PUSTAKA}

\subsection{Pengertian Knowledge Management}

Knowledge Management mencakup tata cara pengelolaan proses penangkapan knowledge, penyerapan dan pendistribusian knowledge, serta penerapan knowledge tersebut. Jika ditinjau dari segi bisnis, maka Amrit Tiwana (2001) mendefinisikannya sebagai berikut:

Knowledge management merupakan pengelolaan knowledge perusahaan dalam menciptakan nilai bisnis (business value) dan menghasilkan keunggulan kompetitif yang berkesinambungan (suistainable competitive advantages) dengan mengoptimalkan proses penciptaan, pengkomunikasian dan pengaplikasian semua knowledge yang dibutuhkan dalam rangka pencapaian tujuan bisnis $^{[2]}$

Sebelum munculnya Knowledge Management, pembedaan antara data, informasi, knowledge dan wisdom tidak begitu menyita perhatian para praktisi bisnis, walaupun sebenarnya proses pengolahan data menjadi informasi dan informasi menjadi knowledge sudah menjadi bagian dari rutinitasnya. Namun, pada Knowledge Management, maka pembedaan data, informasi, knowledge dan 
wisdom tersebut menjadi sangat penting, karena ketidakjelasan pembedaan potensial menimbulkan inefisiensi dan kesalahan dalam penerapan Knowledge Management. Akan ada kemungkinan suatu organisasi menyatakan telah menerapkan knowledge management, tetapi pada kenyataannya yang terjadi baru sampai kepada tahapan Data Management atau Information Management.

Berikut adalah gambaran hubungan datainformation-knowledge-wisdom menurut Tiwana (2000) dalam buku The Knowledge Management Toolkit:

connectedness

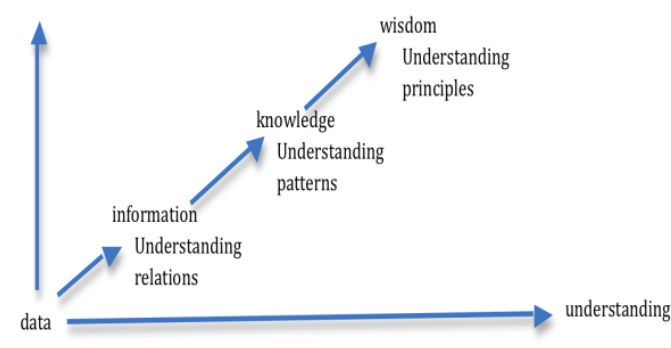

Gambar 1. Hirarki DIKW: dari Data ke Wisdom ${ }^{[2]}$

\subsection{Knowledge Management untuk Komunitas Praktisi (CoP)}

Ada tiga tipe pandangan terhadap $\mathrm{KM}$ yang membantu menjelaskan mengapa KM sangat penting dewasa ini, yaitu KM memberikan manfaat kepada para individu dalam organisasi, komunitas praktisi (Communities of Practise/CoP), dan kepada organisasi itu sendiri ${ }^{[1]}$

Manfaat KM bagi komunitas praktisi antara lain $^{[1]}$ :

a. mengembangkan skill profesional.

b. menyediakan peer-to-peer mentoring.

c. memfasilitasi kolaborasi dan networking yang lebih efektif.

d. mengembangkan kode etik profesional yang bisa diikuti oleh para anggota.

e. mengembangkan "common language".

Pendefinisian komunitas praktisi menurut Etienne Wenger adalah sebagai berikut:

"Communities of practice are groups of people who share a passion for something they do and who interact regularly to learn how to do it better"'[6]

Pendefinisian tersebut kemudian diperkaya lagi oleh Serrat ${ }^{[6]}$ yaitu:

"Communities of practice are groups of likeminded, interacting people who filter, amplify, invest and provide, convene, build and learn and facilitate to ensure more effective creation and sharing of knowledge in their domain".

Ada beberapa role dalam komunitas praktisi, antara lain adalah yang didefinisikan oleh Kim, A dalam bukunya "Community building on the web" "[1] yaitu sebagai berikut: a. Visitors

Yaitu pengguna yang hanya sebagai pengunjung web sekali atau dua kali, yangbisa bergabung ataupun tidak dengan komunitas. Dalam hal ini, pengguna tersebut hanya bermaksud untuk mencari tahu dan mengenali komunitas ini.

b. Novices

Yaitu anggota komunitas yang baru, yang biasanya masih belum terlalu aktif berkontribusi, hingga mereka benar benar telah mempelajari dan memiliki pengetahuan yang cukup mengenai komunitas dan anggota yang lain.

c. Regulars

Yaitu anggota komunitas yang sudah memberikan kontribusi secara reguler dan berinteraksi dengan anggota lain secara berkelanjutan.

d. Leaders

Yaitu anggota komunitas yang meluangkan waktu dan pikirannya untuk memainkan peran yang lebih banyak, antara lain membantu dalam pengoperasian aplikasi bagi komunitas. Dengan kata lain, leaders bisa saja berfungsi sebagai admin komunitas tersebut.

e. Elders

Yaitu anggota komunitas yang memiliki pengetahuan dan kemampuan lebih dalam topik yang dikelola komunitas, serta bersedia untuk menjadi pengasuh sekaligus penasehat bagi semua anggota komunitas dari waktu ke waktu.

informasi yang beredar dari para anggota komunitas agar tidak terjadi pengulangan, duplikasi ataupun kurang berkualitas.

a. Members

Yaitu yang berbagi tanggungjawab dalam mempromosikan CoP, menciptakan ketertarikan atas komunitas, mempromosikan antusiasme di antara para anggota serta memberikan dukungan penuh terhadap kelangsungan CoP.

\subsection{Knowledge Management Tool dan Knowledge Management Strategy}

\subsubsection{Knowledge Management Tool}

Menurut Turban, et al (2004), teknologi KM atau sering disebut KM Tool biasanya terdiri dari tiga komponen utama, yaitu komunikasi, kolabirasi serta storage dan retrieval. KM Tool ini biasanya berupa gabungan platform atau sistem operasi dan aplikasi piranti lunak yang dibangun untuk memfasilitasi proses - proses dalam $\mathrm{KM}^{[2]}$.

Jika mengacu pada siklus SECI Nonaka, maka KM Tool dikembangkan dan dirancang untuk dapat memfasilitasi dan mengakselerasi 
proses sosialisasi, eksternalisasi, kombinasi dan internalisasi ${ }^{[2]}$.

\subsubsection{Knowledge Management Strategy}

Menurut kamus Longman edisi 2003, strategi merupakan tindakan - tindakan yang terencana dalam rangka mencapai sesuatu ${ }^{[2]}$

Sedangkan pendefinisian KM Strategy adalah sebagai berikut:

"Strategi KM merupakan formulasi visi, misi dan objektif strategis dari pengelolaan knowledge yang dijabarkan dari strategi Perusahaan"[2].

Karena itu, menurut Tobing ${ }^{[2]}$, KM bukanlah untuk untuk KM itu sendiri, KM diimplementasikan untuk mendukung keberhasilan strategi Perusahaan. Sukses implementasi KM dapat dilihat dari sejauh mana kontribusi KM dalam mendukung pencapaian target - target Perusahaan, baik jangka pendek maupun jangka panjang.

KM Strategy bisa berisi beragam visi misi, tergantung kebutuhan dan kondisi tiap organisasi $^{[1]}$. Sebagai contoh, KM Strategy yang dikembangkan oleh IFAD, memiliki empat komponen strategis ${ }^{[8]}$ yaitu:

a. strenghtening knowledge sharing and learning process.

b. equipping IFAD with more supportive knowledge sharing and learning infrastructure.

c. fostering partnerships for broader knowledge sharing and learning.

d. promoting a supportive knoledge sharing and learning culture.

Dalam penelitian ini, maka strategi KM harus dapat memberikan konstribusi positif bagi profesi para anggota komunitas praktisi project management ini.

\subsubsection{Faktor - Faktor Penting Dalam Implementasi KM}

Tobing (2007) mengemukakan bahwa faktor - faktor penting yang harus diperhatikan dalam implementasi knowledge management adalah:

a. Manusia
b. Leadership
c. Teknologi
d. Organisasi
e. Learning
Pada faktor Teknologi (KM Tool), Turban et al (2004) mengatakan bahwa KM Tool tersebut biasanya terdiri dari tiga komponen utama, yaitu komunikasi, kolaborasi serta storage dan retrieval. Jika mengacu pada siklus SECI yang dikembangkan oleh Nonaka, maka KM Tool dikembangkan dan dirancang untuk dapat memfasilitasi dan mengakselerasi proses sosialisasi, esternalisasi, internalisasi dan kombinasi ${ }^{[2]}$.

Sedangkan pada implementasi KM untuk project, faktor - faktor pentingnya antara lain sebagaimana yang dikemukakan pada salah satu penelitian yang dilakukan oleh Frank Lindner dan Andreas Wald, yang mereka tuangkan dalam artikel berjudul "Success Factors of Knowledge Management in Temporary Organization" pada Jurnal Internasional Project Management tahun 2010 ini.

Menurut mereka, dengan mulai berkembangnya organisasi - organisasi yang bersifat temporer seperti project dan program, di mana ada peningkatan kebutuhan akan knowledge sebagai salah satu sumber daya kritikal, sedangkan terdapat keterbatasan waktu untuk mengimplementasikan knowledge sharing, maka mereka melakukan sebuah penelitian untuk mengidentifikasi faktor faktor keberhasilan pengembangan dan pengimplementasian knowledge management pada organisasi temporer tersebut.

Penelitian yang dilakukan Lindner dan Wald dengan cara survei melalui pemberian pengisian kuisionerkepada 8000 anggota dan orang - orang terkait yang tergabung dalam GPM (German Association for Project Management) dan anggota IPMA (International Project Management Association) itu menghasilkan rumusan faktor - faktor keberhasilan pengembangan dan pengimplementasian KMS pada project management seperti yang ditunjukkan pada gambar 2. 


\begin{tabular}{|c|c|c|}
\hline Dimension & Hypothesis & Result \\
\hline \multirow{6}{*}{ Culture and leadership } & HC 1 Knowledge culture has a positive effect on PKM-effectiveness. & Support \\
\hline & HC 2.1 Management commitment has a positive effect on PKM-effectiveness. & Support \\
\hline & HC 2.2 Management commitment has a positive effect on knowledge culture. & Support \\
\hline & HC 3.1 Mistake tolerance has a positive effect on knowledge culture. & Support \\
\hline & HC 3.2 Project culture has a positive effect on knowledge culture & Support \\
\hline & HC 3.3 Informal networks have a positive effect on knowledge culture. & Support \\
\hline \multirow[t]{9}{*}{ Organization and processes } & HO 1 Systematic PK processes have a positive effect on PKM-effectiveness. & Support \\
\hline & HO 2 The organization of PKM has a positive effect on PKM-effectiveness. & Support \\
\hline & HO 3.1 The maturity of the PM-methodology has a positive effect on PKM-effectiveness. & Support \\
\hline & HO 3.2 The maturity of the PM-methodology has a positive effect on the organization of PKM. & Reject \\
\hline & HO 3.3 The maturity of the PM-methodology has a positive effect on PKM-processes. & Support \\
\hline & HO 4.1 The institutionalization of multi-PM/KM has a positive effect on PKM-effectiveness. & Support \\
\hline & HO 4.2 The institutionalization of multi-PM/KM has a positive effect on the organization of PKM. & Support \\
\hline & HO 4.3 The institutionalization of multi-PM/KM has a positive effect on PKM-processes. & Support \\
\hline & HO 5 Evaluation and controlling of KM activities positively affects PKM-effectiveness & Support \\
\hline \multirow[t]{3}{*}{ ICT-systems } & HS 1.1 ICT support has a positive effect on PKM-effectiveness. & Support \\
\hline & HS 1.2 The use of systems to support communication has a positive effect on ICT support. & Support \\
\hline & HS 1.3 The use of systems to support storage has a positive effect on ICT support. & Support \\
\hline
\end{tabular}

Gambar 2. Faktor Keberhasilan Pengimplementasian KMS pada PM ${ }^{[4]}$

Dari gambar tersebut, bisa kita pelajari bahwa faktor - faktor keberhasilan pekerjaan knowledge management pada organisasi yang bersifat temporer seperti project dan program antara lain adalah yang terdapat pada hasil survei tersebut (yang diberi tanda "support”).
Mempelajari faktor - faktor penting yang dikemukakan oleh Tobing serta faktor -faktor keberhasilan PKM pada penelitian Lindner dan Wald di atas, maka pada penelitian ini, peneliti akan melakukan pemodelan knowledge management system berbasis webdengan menitikberatkan pada hal - hal berikut (tabel 1):

Tabel 1. Fokus Pemodelan KMSPM

\begin{tabular}{|c|c|c|}
\hline \multicolumn{2}{|r|}{ Kunci Keberhasilan } & Kegiatan \\
\hline Learning & $\begin{array}{l}\text { Budaya KM memberikan pengaruh } \\
\text { positif pada efektifitas PKM }\end{array}$ & \multirow{3}{*}{$\begin{array}{l}\text { Menyusun berbagai Standard Operating } \\
\text { Procedures (SOP) dengan maksimal, agar } \\
\text { budaya berbagi knowledge pada KMS ini bisa } \\
\text { berjalan lancar. } \\
\text { SOP awal akan didesain oleh peneliti (sebagai } \\
\text { admin awal), selanjutnya bisa dikembangkan } \\
\text { sesuai masukan dari anggotakomunitas }\end{array}$} \\
\hline \multirow{3}{*}{ Leadership } & $\begin{array}{l}\text { Komitmen Manajemen memberikan } \\
\text { pengaruh positif pada efektifitas PKM }\end{array}$ & \\
\hline & $\begin{array}{ll}\text { Komitmen } & \text { Manajemen memberikan } \\
\text { pengaruh positif pada budaya } \\
\text { knowledge }\end{array}$ & \\
\hline & $\begin{array}{l}\text { Toleransi kesalahan berpengaruh positif } \\
\text { pada budaya knowledge }\end{array}$ & \multirow{2}{*}{$\begin{array}{l}\text { Menyediakan fasilitas pada KMS agar tiap } \\
\text { anggota bisa saling memberikan feedback } \\
\text { terhadap setiap knowledge yang tersedia, } \\
\text { sehingga dimungkinkan adanya proses koreksi } \\
\text { oleh sesama anggota komunitas, dalam rangka } \\
\text { penyelenggaraan proses evaluasi dan kontrol } \\
\text { aktivitas KM serta pengembangan budaya } \\
\text { sharing. }\end{array}$} \\
\hline Manusia & $\begin{array}{l}\text { Evaluasi dan kontrol aktivitas KM akan } \\
\text { mempengaruhi efektifitas PKM }\end{array}$ & \\
\hline \multirow{3}{*}{ Teknologi } & $\begin{array}{l}\text { Dukungan ICT memberikan pengaruh } \\
\text { positif pada efektifitas PKM }\end{array}$ & \multirow{3}{*}{$\begin{array}{l}\text { Mengembangkan KMS dengan maksimal, } \\
\text { dengan memperhatikan faktor kelengkapan dan } \\
\text { kemudahan (ketepatan dan kecepatan) } \\
\text { penggunaan. } \\
\text { Memilih tool yang tepat untuk pengembangan } \\
\text { KMS tersebut. }\end{array}$} \\
\hline & $\begin{array}{l}\text { Penggunaan sistem untuk mendukung } \\
\text { komunikasi memberikan pengaruh } \\
\text { positif pada dukungan ICT }\end{array}$ & \\
\hline & $\begin{array}{l}\text { Penggunaan sistem untuk mendukung } \\
\text { penyimpanan memberikan pengaruh } \\
\text { positif pada dukungan ICT }\end{array}$ & \\
\hline
\end{tabular}

Selain memperhatikan faktor keberhasilan KM, maka sebaiknya rencana implementasi KM juga memperhatikan faktor kegagalan yang biasa terjadi agar bisa menghindari hal tersebut. Eisaku Oshima ${ }^{[7]}$ dalam papernya menyebut faktor kegagalan tersebut dengan istilah "The Three Traps in $K M^{\text {,[7] }}$, yaitu:

\section{a. Lack of interest in knowledge sharing \\ b. Knowledge is not used \\ c. KM does not continue}

Menurut Oshima, bahkan beberapa perusahaan yang sudah menerapkan KM secara advanced seperti Asahi Breweries dan Fuji Xerox juga pernah mengalami ketiga hal tersebut. Cara penanganan dan penyelesaian tiga 
masalah itu bisa berbeda - beda disesuaikan dengan budaya dan tujuan suatu Perusahaan ${ }^{[7]}$.

\section{METODE PENELITIAN}

Metode penelitian yang digunakan dalam penelitian ini yaitu:

1. Studi Literatur

Merupakan kegiatan pemahaman teoriteori Project Management melalui pedoman buku PMBOK, materi training dan presentasi Project Management Professional (PMP), dalam rangka pengumpulan basic explicit knowledge.

Selain itu, mencakup juga kegiatan studi literatur melalui internet (browsing) dalam rangka pengumpulan informasi tentang tools yang bisa digunakan untuk KMS system.

2. Wawancara

Merupakan Kegiatandiskusi dengan beberapa praktisi Project Management dalam rangka pengumpulan basic tacit knowledge.

3. Lain - lain

Yaitu pengumpulan knowledge melalui ekstraksi pengalaman peneliti bergerak di bidang project management selama tiga tahun (sebagai Project Admin, Knowledge Management Administrator dan Project Control).

Sebagaimana yang telah disebutkan di awal, ini mengambil bidang keilmuan project management sebagai objek penelitian, dengan metodologi mengacu pada siklus knowledge management terintegrasi yang digambarkan oleh Kimiz Dalkir (Gambar 3), serta memfasilitasi proses konversi knowledge sesuai dengan yang dikembangkan oleh Nonaka dan Takeuchi (Gambar 4).

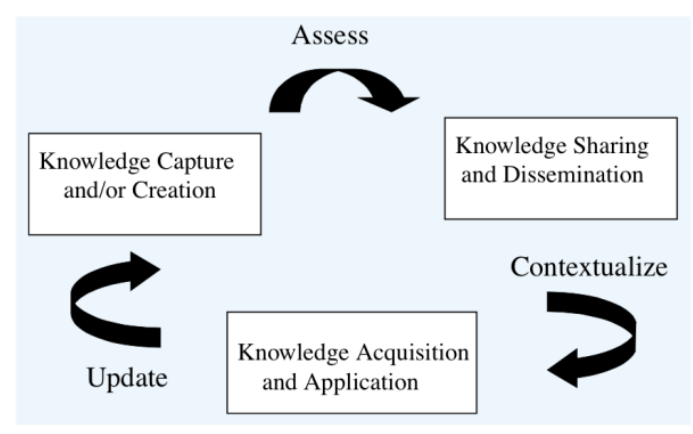

Gambar 3. Siklus Knowledge Management yang Terintegrasi ${ }^{[1]}$

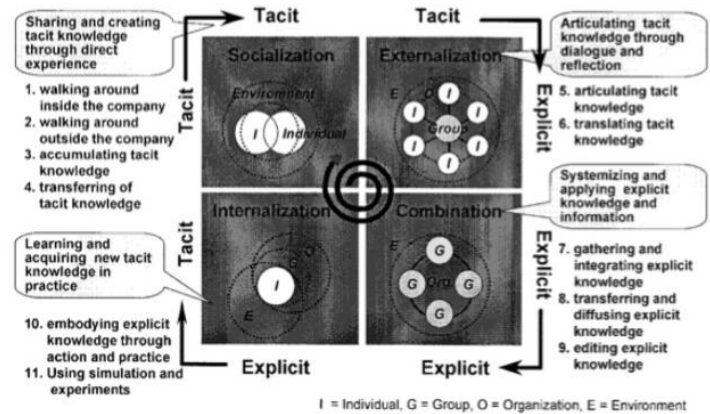

Gambar 4. Model Konversi Knowledge Nonaka dan Takeuchi ${ }^{[1]}$

Karena itu, secara garis besar, pelaksanaan roadmap pemodelan KMS berbasis web ini terbagi tiga tahapan, sebagai berikut:

1. Tahap Pembentukan Knowledge Dasar

Tahap ini merupakan tahap awal dan pondasi dari keseluruhan KMS roadmap. Pada tahap ini akan dilakukan proses knowledge capturing untuk bidang project management, hingga terbentuk pemetaan knowledge dasar tersebut, atau dikenal dengan istilah knowledge taxonomy. selain sebagai pondasi awal KMS, knowledge dasar (taxonomy) ini juga nantinya akan menjadi pedoman dalam pengembangan fitur - fitur KMS.

Pembentukan knowledge dasar ini dilakukan melalui dua proses sebagai berikut:

a. Capturingknowledge

Merupakan proses pencarian dan pengambilan knowledge, baik yang explicit maupun tacit, menggunakan cara pemodelan Nonaka dan Takeuchi.

b. Clarifying knowledge

Merupakan proses pendefinisian dan penentuan klasifikasi knowledge, dalam rangka penyusunan taxonomy.

2. Tahap Perencanaan KM Tool

Tahap ini dimulai dengan pemilihan Tool (untuk memilih antara Alfresco dan Knowledge ManagementTree), dilanjutkan dengan perencanaan menu dan penggambaran mock up, berdasarkan pada taxonomy yang didapat dari tahap pertama.

3. Tahap Perancangan KM Strategy

Dua Hal - hal yang akan dikerjakan pada tahap ini yaitu:

a. Penyusunan beberapa Standard Operating Procedure (SOP)

Pada tahap ini akan disusun beberapa SOP dasar untuk memudahkan penggunaan KMSnantinya. Pada penyusunan ini, SOP umum yang akan disusun adalah SOP penggunaan dasar saja, meliputi:

(1) prosedur keanggotaan komunitas

(2) prosedur knowledge sharing antar Anggota komunitas (termasuk penentuan reward) 
(3) prosedur pengelolaan dan pemeliharaan KMSPM oleh Admin.

Pada perkembangannya nanti, diperbolehkan untuk menyusun SOP tambahan atau perbaikan SOP yang sudah ada, melalui diskusi dan kesepakatan semua Anggota komunitas. b. Penyusunan strategi evaluasi performansi KMS.

Tahap ini akan menggambarkan proses evaluasi performansi KMSPM melalui metode pengukuran Knowledge Management Maturity Model (KMMM).

Berikut gambaran perencanaan pelaksanaan KMS roadmap ini:

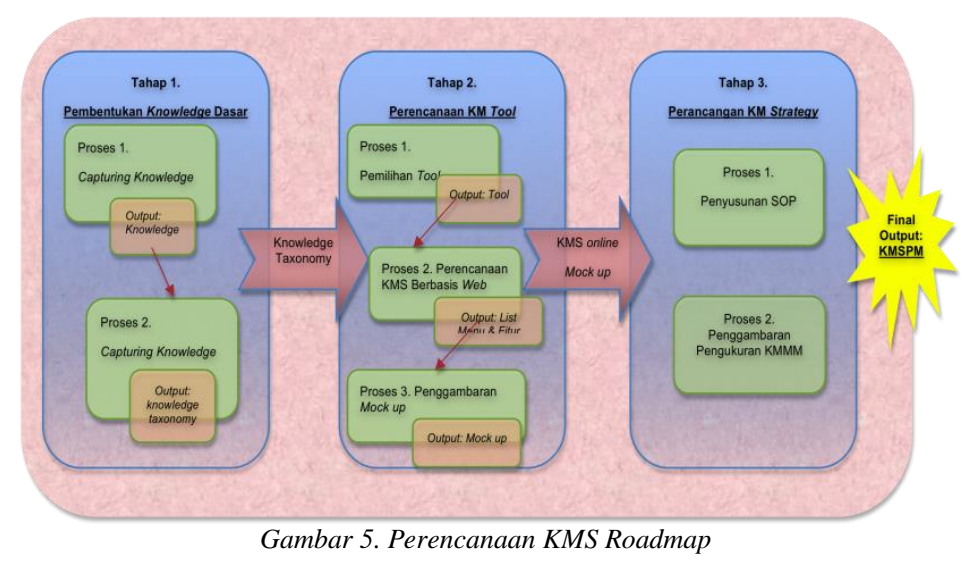

4. HASIL DAN PEMBAHASAN

Pemodelan Knowledge Management Berbasis Web (KMSPM)

\section{Pembentukan Knowledge Dasar}

Berdasarkan metodologi penelitian ini, maka knowledge dasar yang didapat untuk Project Management adalah proses, knowledge area, dokumentasi, tools, stakeholder dan project management office, dengan taxonomy seperti yang ditunjukkan oleh gambar 6 .

\section{Perencanaan KM Tool \& KM Team}

Setelah membandingkan dua jenis tool, yaitu Alfresco dan KnowledgeTree (tabel 2), maka dipilih KnowledgeTree sebagai KM tool untuk pemodelan KMS berbasis web ini, dengan fitur seperti yang ditunjukkan oleh gambar 7 .
Sedangkan untuk pengkategorian pengguna (yang sekaligus sebagai KM team), maka pada pemodelan KMS ini dengan mengacu pada teori community of practises role yang dikemukakan oleh Kim, pengguna dibedakan menjadi empat kategori role, yaitu: (1) Novices ; (2) Regulars ; (3) Leaders ; (4) Elders (merupakan praktisi yang sudah memperoleh sertifikat Project Management Professional/PMP dari Project Management Institute).

Tabel 2. Perbandingan Tool KnowledgeTree dengan Alfresco

\begin{tabular}{|l|l|l|}
\hline Fasilitas & KnowledgeTree & Alfresco \\
\hline Jenis Aplikasi & $\begin{array}{l}\text { Berbasis web, digunakan langsung } \\
\text { dengan domain pada internet }\end{array}$ & $\begin{array}{l}\text { Berbasis } \text { open source dengan } \\
\text { menggunakan koneksi intranet (aplikasi } \\
\text { berupa portal), sehingga harus diinstal } \\
\text { pada server intranet }\end{array}$ \\
\hline Penggunaan & $\begin{array}{l}\text { Menyesuaikan dengan paket fitur } \\
\text { yang sudah tersedia }\end{array}$ & $\begin{array}{l}\text { Mengkustomisasi sesuai dengan } \\
\text { kebutuhan, melalui pengkodingan pada } \\
\text { progam aplikasi }\end{array}$ \\
\hline $\begin{array}{l}\text { Fitur untuk } \\
\text { mendukung KMS }\end{array}$ & $\begin{array}{l}\text { File sharing, document workflow } \\
\text { dan ada integrasi dengan microsoft } \\
\text { office }\end{array}$ & $\begin{array}{l}\text { File sharing, integrasi dengan Windows } \\
\text { Explorer }\end{array}$ \\
\hline $\begin{array}{l}\text { Tampilan antar muka } \\
\text { interface })\end{array}$ & $\begin{array}{l}\text { Sederhana, dengan menu yang } \\
\text { terstruktur dan mudah digunakan } \\
\text { serta menarik (user-friendly) }\end{array}$ & $\begin{array}{l}\text { Rumit dan kurang terstruktur, serta } \\
\text { tampak sangat formal sehingga agak } \\
\text { membosankan }\end{array}$ \\
\hline Sistem Sekuriti & Ada & Tidak ada \\
\hline
\end{tabular}




\begin{tabular}{|l|l|l|}
\hline Free Trial & $\begin{array}{l}14 \text { hari, bisa menggunakan fitur dan } \\
\text { menu standar saja }\end{array}$ & $\begin{array}{l}30 \text { hari, tapi tidak diketahui seberapa } \\
\text { banyak menu yang bisa digunakan. }\end{array}$ \\
\hline Harga & $\begin{array}{l}\text { Relatif terjangkau, dengan berbagai } \\
\text { variasi paket harga dan fitur }\end{array}$ & $\begin{array}{l}\text { Tidak diketahui (harus menghubungi } \\
\text { bagian marketingnya langsung) }\end{array}$ \\
\hline
\end{tabular}

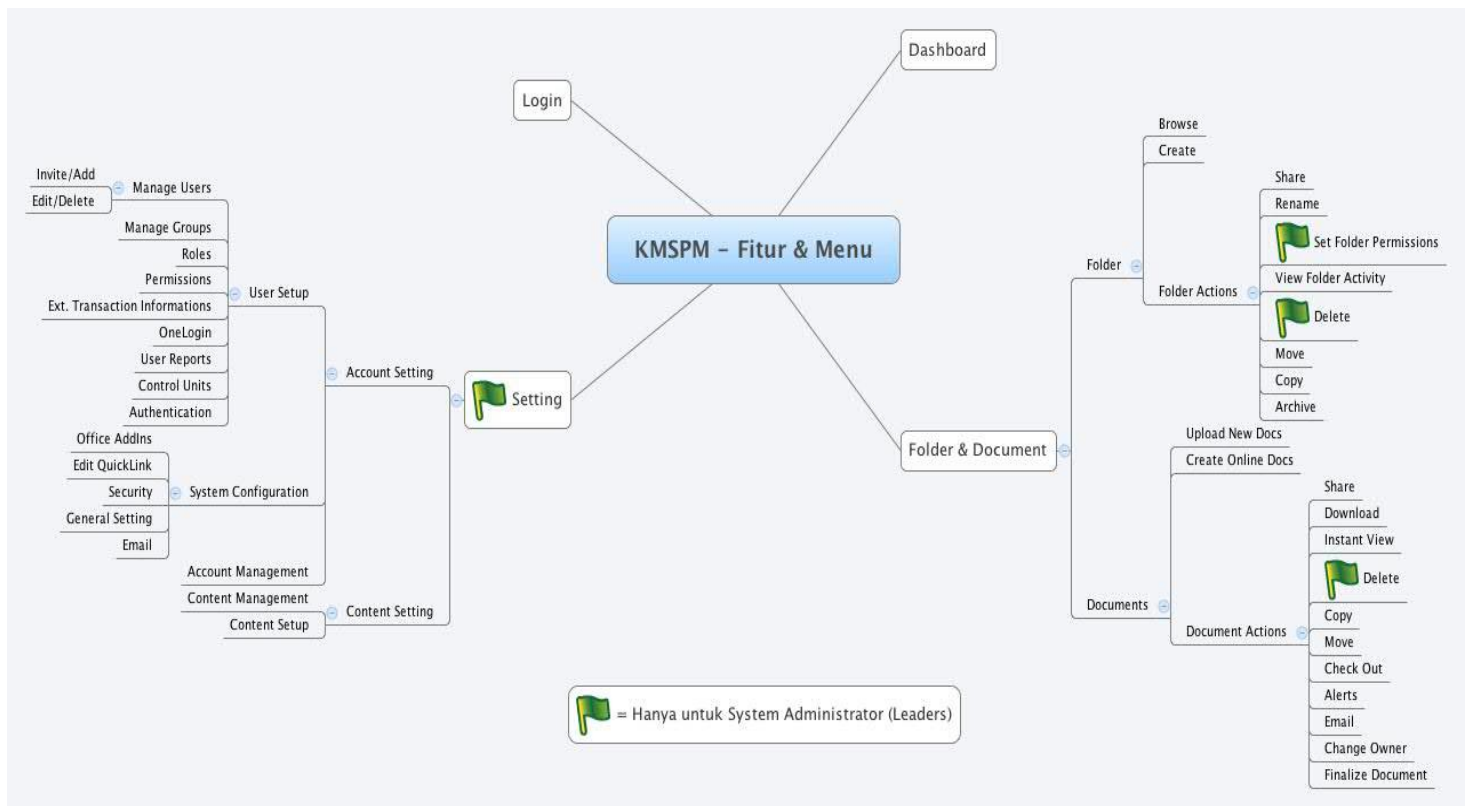

Gambar 6. Knowledge Taxonomy Dasar Untuk Project Management

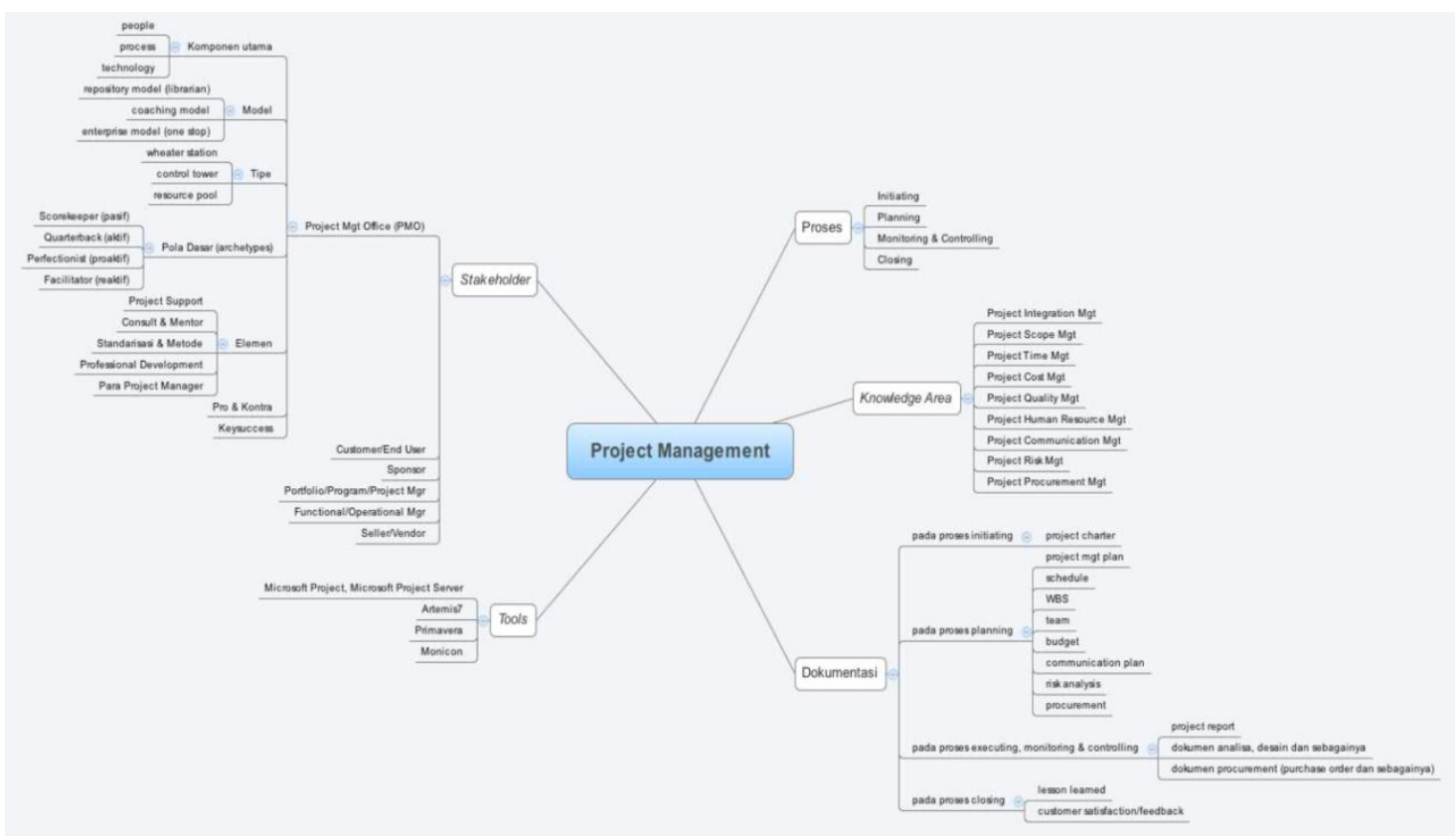

Gambar 7. Pemetaan fitur dan тепи KMSPM 


\section{Perancangan KM Strategy}

Melalui penyelarasan dengan strategi komunitas praktisi, maka dikembangkan sebuah strategi KM yang terdiri dari tiga strategi utama dan mendasar untuk menunjang keberhasilan implementasinya, yaitu sebagai berikut:

a. Mengembangkan ketentuan mengenai tata cara memberi atau menerima knowledge, agar tertib dan tidak membingungkan anggota.

b. Mengembangkan kebijakan sistem rewards-and-punishment bagi anggota yang aktif dan tidak aktif berkontribusi dalam pengadaan dan penyebaran knowledge. Hal ini penting dilakukan dalam upaya pengembangan budaya knowledge - sharing yang optimal.

c. Menyusun cara pengukuran kinerja KMSPM, agar diketahui sejauh mana perkembangan KMSPM, untuk membantu menentukan tindak lanjut dalam upaya peningkatan kualitasnya.

Strategi - strategi yang telah ditentukan tersebut selanjutnya dituangkan dalam perincian Standard Operating Procedure (SOP) penggunaan KMSPM dan penyusunan langkah - langkah yang diperlukan dalam proses pengukuran kinerja KMSPM, untuk membantu anggota memahami tata cara penggunaan dan berbagai ketentuan atau kebijakan yang ada dan mengetahui sejauh mana perkembangan kinerja KMSPM ini, yaitu sebagai berikut:

\section{a. Prosedur keanggotaan komunitas.}

Keanggotaan komunitas terbuka bagi praktisi project management Indonesia yang ingin bergabung. Namun, karena KMSPM ini tidak bisa diakses atau dilihat oleh pengguna internet yang belum menjadi anggota, maka prosedur keanggotaan komunitas adalah sebagai berikut:

(1) Tiap Leader menulis informasi mengenai komunitas dan tujuan dari adanya KMSPM kepada sesama rekan praktisi project management, melalui berbagai media pribadi, seperti blog, email atau akun jejaring sosial.

(2) Tiap Leader mengirimkan email undangan dari menu invite user pada KMSPM, atau langsung menuliskan data anggota baru pada fitur Add User.

(3) Calon Anggota (Kandidat Member) yang ingin bergabung, bisa mengkonfirmasi keanggotaan dengan cara mengklik link domain yang terdapat pada email undangan, kemudian melakukan login sesuai dengan data email yang dimilikinya (ID dan password).

(4) Calon Anggota (Kandidat Member) yang tidak ingin bergabung, bisa mengabaikan saja email undangan tersebut (email undangan hanya akan dikirim satu kali, sehingga tidak akan mengganggu para Kandidat Member yang tidak ingin bergabung).

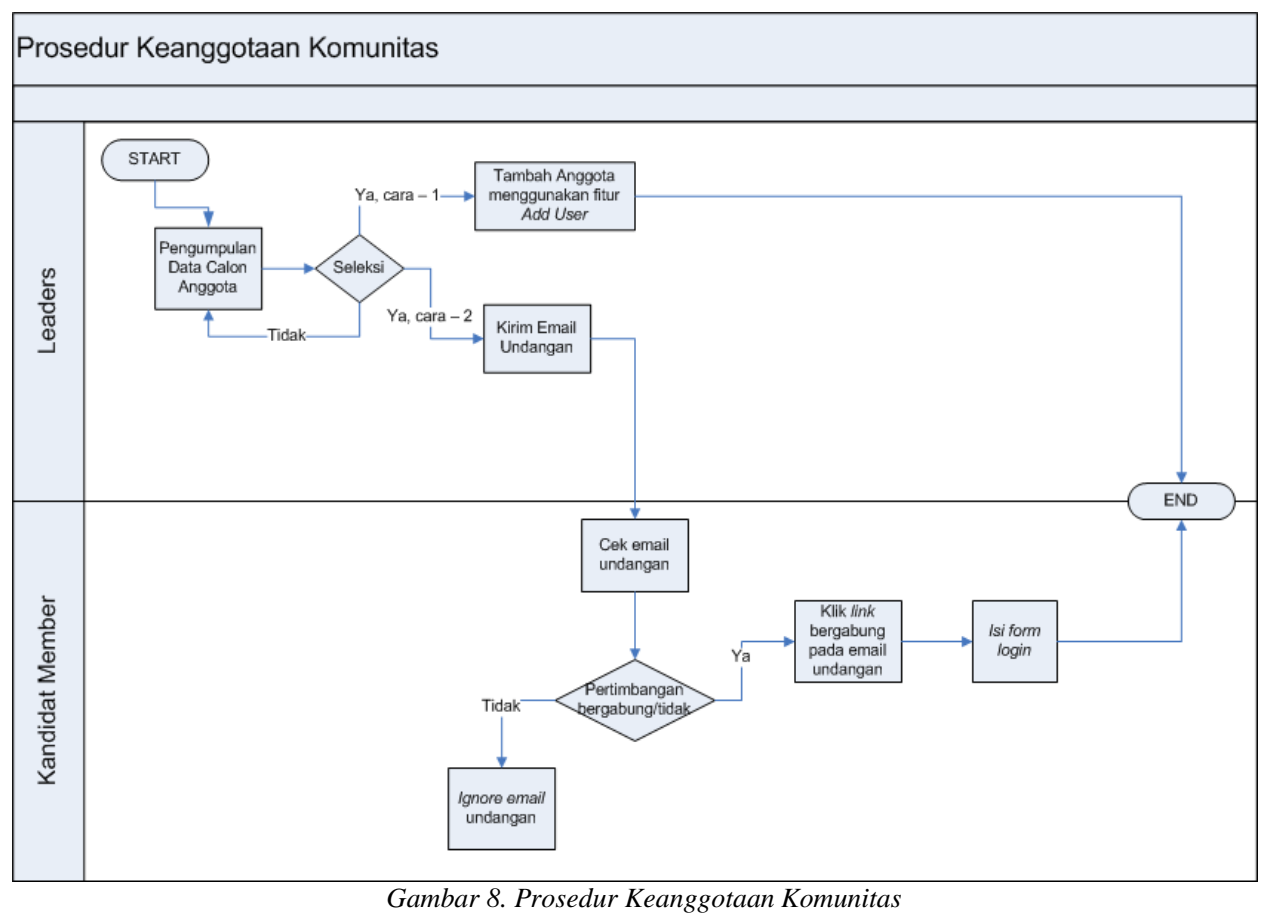

\section{b. Prosedur Knowledge Sharing.}

Prosedur ini memiliki beberapa ketentuan mendasar bagi anggota komunitasnya, yaitu:
(1) Knowledge yang akan dimasukkan ke KMSPM haruslah yang valid (terjamin 
keabsahan dan kebenarannya) dan berkualitas.

(2) Knowledge yang akan dimasukkan ke KMSPM, yang mengandung pernyataan pernyataan dari pakar atau sumber lain, maka harus disebutkan keterangan sumber tersebut.

(3) Anggota Regulars yang akan memasukkan knowledge baru ke KMSPM, bisa melakukannya melalui menu upload file. Selanjutnya, knowledge tersebut bisa dilihat atau diunduh (download) oleh anggota lain.

(4) Jika Anggota Leaders (yang beranggotakan juga salah satu dari Elders) menilai knowledge baru tersebut kurang valid atau kurang berkualitas, maka berhak menghapusnya kemudian harus mengirimkan email konfirmasi penghapusan kepada Anggota Regulars yang mengunggah (upload) - nya.

(5) Anggota lain (baik Novices maupun Regulars lain) boleh mengunduh semua knowledge yang terdapat pada KMSPM, dan harus memberikan respon pada knowledge yang ada, baik komentar ataupun balasan dengan mengunggah knowledge yang berkaitan dengan knowledge tadi (yang lebih up-to-date atau sekedar memperkaya dengan referensi yang lain).

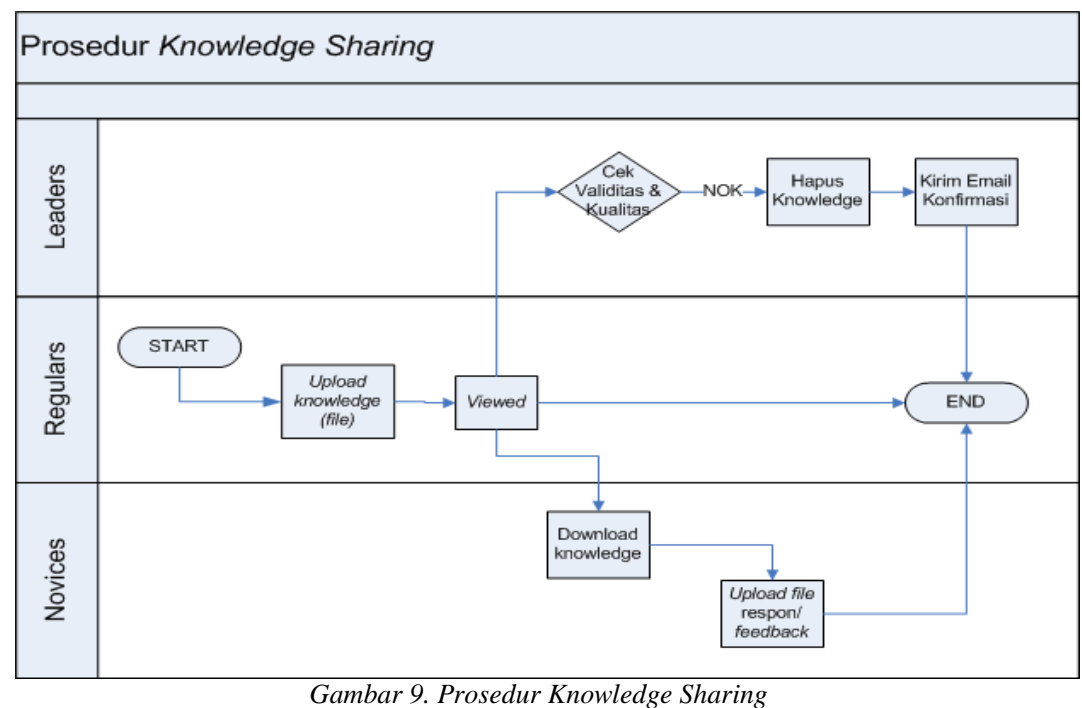

\section{c. Prosedur Pengelolaan Dan Pemeliharaan KMSPM Oleh Leaders}

Prosedur ini menangani dua macam pengelolaan, yaitu pengelolaan users dan pengelolaan content pada KMSPM.

Untuk pengelolaan users, terdiri dari beberapa ketentuan mendasar, yaitu:

(1) Anggotayang tidak aktif melakukan kegiatan KM pada KMSPM akan dihapus dari keanggotaan komunitas sehingga tidak bisa mengakses lagi domain KMSPM ini, setelah terlebih dahulu dikirimkan email pemberitahuan mengenai status aktivitasnya.

(2) Sebanyak 10\% dari Anggota Regulars dan Leaders, yang dinilai oleh Anggota Leaders paling sering berkontribusi pada perkembangan knowledge di KMSPM ini akan mendapatkan rewards dinobatkan sebagai "knowledge worker of the month". Evaluasi ini dilakukan oleh Anggota Leaders setiap bulan.

(3) Anggota Leaders akan diganti setiap periode enam bulan sekali. Anggota Leaders berikutnya dipilih dari anggota yang aktif berkontribusi pada KMSPM selama periode terakhir. Khusus untuk anggota yang mendapatkan tiga kali rewards "knowledge worker of the month" tidak dikenakan tugas sebagai Leaders pada periode baru ini, tapi pada periode selanjutnya hal ini tidak berlaku bagi orang yang sama. 


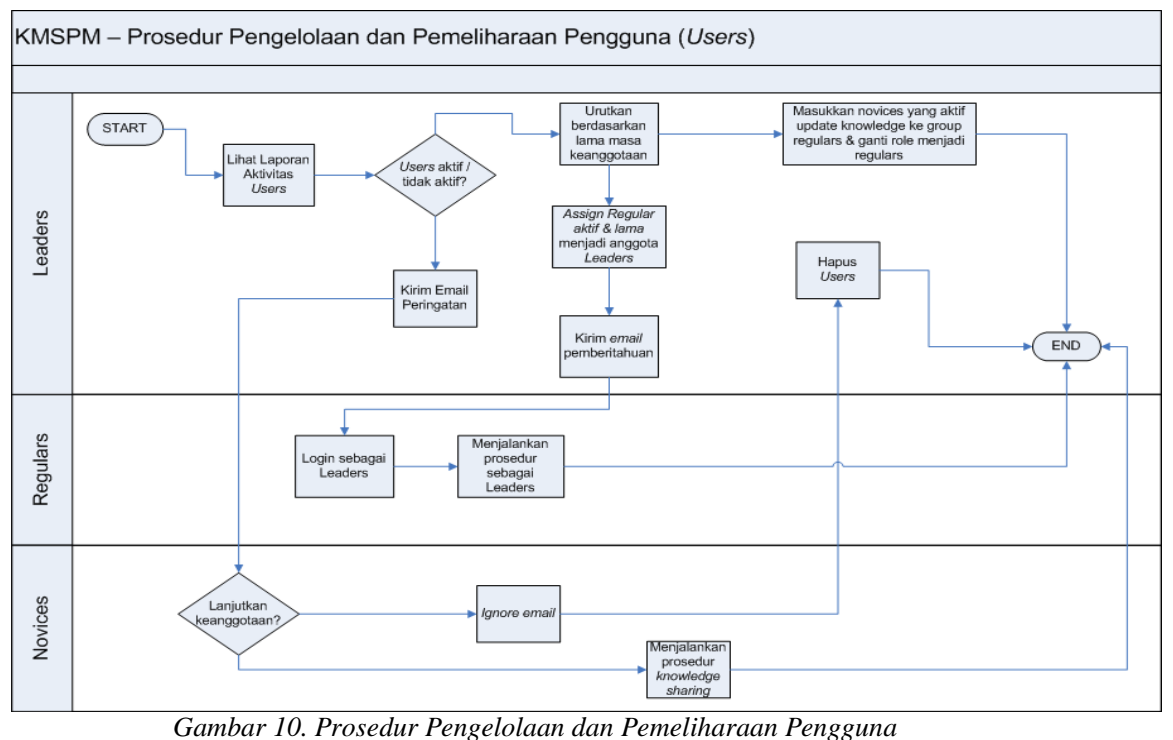

Untuk pengelolaan content, beberapa ketentuan mendasar yaitu:

(1) Anggota Leaders (yang beranggotakan juga salah satu dari Elders) mengevaluasi (review) knwoledge yang terdapat pada KMSPM. Jika dianggap sudah tidak relevan lagi, maka akan mengirimkan email pemberitahuan kepada pengunggah knowledge tersebut.

(2) Pengunggah knowledge yang sudah mendapat email pemberitahuan harus melakukan update pada knowledge - nya tersebut. Jika tidak, maka Anggota Leaders akan menghapus knowledge itu.

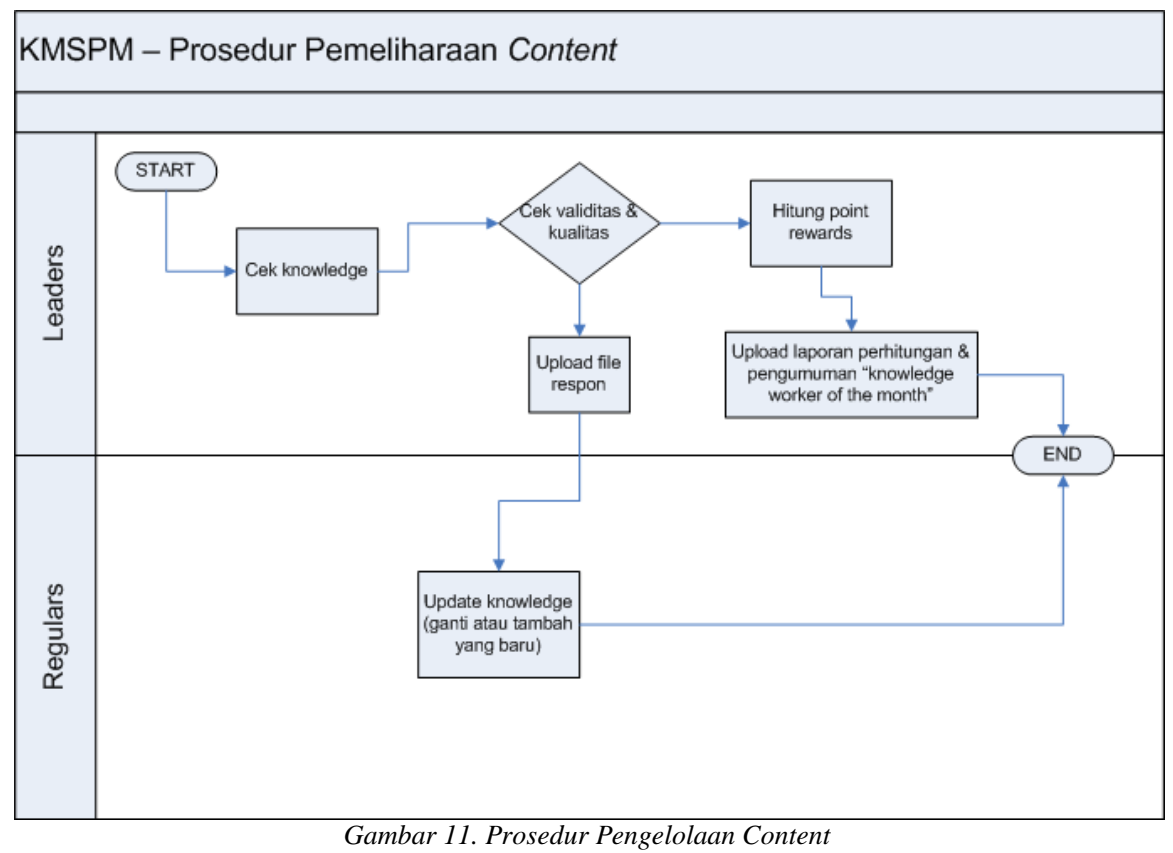

\section{Pengukuran Performansi dengan Metode KMMM \\ Jika KMSPM ini sudah} diimplementasikan, maka setelah satu tahun pertama akan dilakukan pengukuran perfomansi kualititatif dengan menggunakan metode $\mathrm{KMMM}^{[3]}$ dengan tujuan untuk mendapatkan gambaran nyata mengenai perkembangan website KMSPM dalam rangka membantu perencanaan perkembangannya nanti.
Selanjutnya, pengukuran akan dilakukan secara berkala setiap tahun.

Proses pendefinisian KMMM ini nantinya akan dilakukan melalui sistem pembagian kuestioner kepada setiap anggota komunitas, dengan proses assessment sebagai berikut:

a. Pengumpulan dan konsolidasi data, yang dilakukan melalui pengisian kuestioner oleh setiap anggota komunitas, yang dokumennya bisa diunduh dari KMSPM web. Proses ini bertujuan untuk 
mendapatkan gambaran jelas mengenai kondisi perkembangan KMSPM, apakah sedang berada pada level initial, repeated, defined, managed atau optimizing, sesuai pendefinisian piramida KMMM.

b. Konsensus solusi dan perencanaan tindak lanjut, yang bertujuan untuk mendiskusikan dan mencari kesepakatan mengenai solusi dan rencana tindak lanjut pengembangan KMSPM, apakah ada yang perlu diperbaiki agar level yang sudah dicapai bisa dimaksimalkan, atau ditingkatkan ke level selanjutnya pada piramida KMMM.

c. Upload dokumen hasil assessment KMMM, sebagai pertanggungjawaban dan agar diketahui oleh semua anggota komunitas.

d. Proses terakhir, yaitu realisasi dari perencanaan tindak lanjut improvement KMMM.

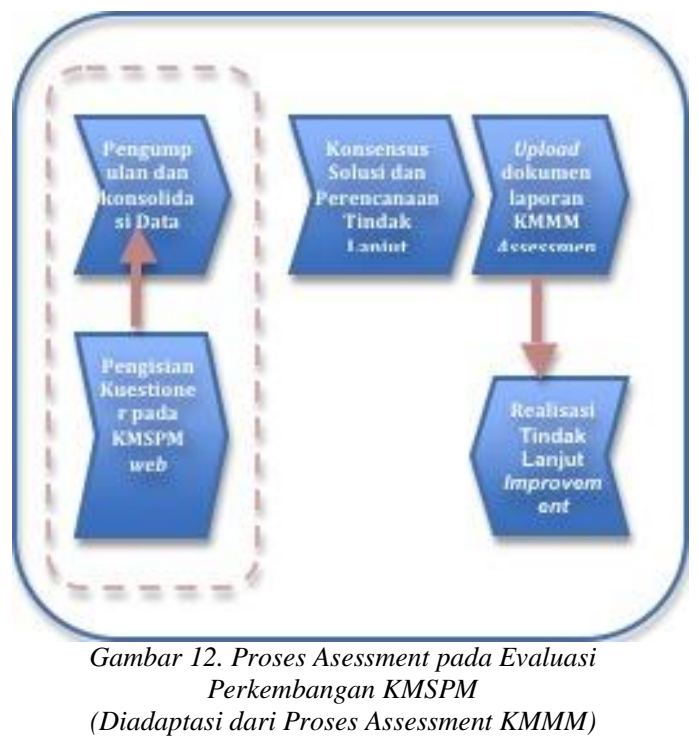

\section{KESIMPULAN}

Dengan adanya penelitian ini, maka peneliti mengharapkan bisa membantu memberikan gambaran pada praktisi knowledge management pada umumnya tentang bagaimana mengembangkan konsep knowledge management yang baik dan berdaya guna tinggi. Selain itu, dengan adanya konsep pemodelan KMSPM ini diharapkan dapat membantu para praktisi serta peminat project management hal hal berikut:

1. Mengenal secara cepat mengenai keilmuan project management melalui pemetaan knowledge yang berkaitan dengan project management.

2. Memudahkan pertukaran informasi mengenai project management di antara sesama praktis dan peminatnya, melalui budaya knowledge sharing yang dikembangkan dan difasilitasi oleh KMSPM ini.

3. Dengan adanya pengembangan pengetahuan akan proejct management best practise, diharapkan bisa memperkaya knowledge dan skill anggota komunitas KMSPM ini.

Demi penyempurnaan konsep pemodelan ini, maka masih diperlukan dukungan pengetahuan dari praktisi atau pakar project management yang lain. kemudian agar implementasinya nanti bisa terlaksana sesuai dengan apa yang telah dimodelkan, maka sangat diperlukan komitmen yang tinggi dari semua pelaksana implementasi dan anggota komunitas yang nantinya terbentuk, untuk tetap mendukung dan berkontribusi dalam pengelolaan dan pengembangan KMSPM ini.

\section{DAFTAR PUSTAKA}

[1] Dalkir, Kimiz. Knowledge Management in Theory and Practise. Elsevier Inc., Butterworth-Heinemann. USA. 2005

[2] Tobing, Paul L. Knowledge Management Konsep Arsitektur dan Implementasi. GrahaIlmu, Bandung. 2007

[3] Langen, Manfred DR. Holistic Development of KM with the KM Maturity Model. http://www.kmmm.org, diakses terakhir tanggal 20 November 2010.

[4] Lindner, Frank and Wald, Andreas. Success Factors of Knowledge Management in Temporary Organizations. International Journal, http://www.sciencedirect.com, diakses terakhir tanggal14 Desember 2010.

[5] Nonaka, Ikujiro and Toyama, Ryoko. The Knowledge-Creating Theory Revisited: Knowledge Creation as a Synthesizing Process. International Journal, http://www.iwp.jku.at, diakses terakhir tanggal 3 Februari 2010.

[6] Serrat, Olivier. Building Communities of Practice. Asian Development Bank. http://www.adb.org, diakses terakhirt anggal 3 Februari 2010.

[7] Oshima, Eisaku. Knowledge Management (KM). RCS Institute, Inc. http://webfsktm2.fsktm.um.edu.my, diakses terakhir tanggal 3 Februari 2010.

[8] IFAD. Knowledge Management Strategy (2007). http://www.ifad.org/pub, diakses terakhir tanggal 7 Februari 2011. 